\title{
ARTICLE \\ Is the combinational administration of doxorubicin and glutathione a reasonable proposal?
}

Bo-yu Shen ${ }^{1}$, Chong Chen ${ }^{1}$, Yang-fan $\mathrm{Xu}^{1}$, Jia-jia Shen ${ }^{1}$, Hui-min Guo ${ }^{1}$, Hao-feng Li ${ }^{1}$, Xi-nuo Li ${ }^{1}$, Dian Kang ${ }^{1}$, Yu-hao Shao ${ }^{1}$, Zhang-pei Zhu ${ }^{1}$, Xiao-xi Yin ${ }^{1}$, Lin Xie ${ }^{1}$, Guang-ji Wang ${ }^{1}$ and Yan Liang ${ }^{1}$

The combinational administration of antioxidants and chemotherapeutic agents during conventional cancer treatment is among one of the most controversial areas in oncology. Although the data on the combinational usage of doxorubicin (DOX) and glutathione (GSH) agents have been explored for over 20 years, the duration, administration route, and authentic rationality have not yet been fully understood yet. In the current study, we systematically investigated the pharmacokinetics (PK) and pharmacodynamics (PD) with both in vivo and in vitro models to elucidate the influence of GSH on the toxicity and efficacy of DOX. We first studied the cardioprotective and hepatoprotective effects of GSH in Balb/c mice, H9c2, and HL7702 cells. We showed that coadministration of exogenous GSH (5,50, and $500 \mathrm{mg} / \mathrm{kg}$ per day, intragastric) significantly attenuated DOX-induced cardiotoxicity and hepatotoxicity by increasing intracellular GSH levels, whereas the elevated GSH concentrations did not affect the exposure of DOX in mouse heart and liver. From PK and PD perspectives, then the influences of GSH on the chemotherapeutic efficacy of DOX were investigated in xenografted nude mice and cancer cell models, including MCF-7, HepG2, and Caco-2 cells, which revealed that administration of exogenous GSH dose-dependently attenuated the anticancer efficacy of DOX in vivo and in vitro, although the elevated GSH levels neither influenced the concentration of DOX in tumors in vivo, nor the uptake of DOX in MCF-7 tumor cells in vitro. Based on the results we suggest that the combined administration of GSH and DOX should be contraindicated during chemotherapy unless DOX has caused serious hepatotoxicity and cardiotoxicity.

Keywords: doxorubicin; glutathione; cardioprotection; hepatoprotection; chemotherapeutic efficacy; antioxidants

Acta Pharmacologica Sinica (2019) 40:699-709; https://doi.org/10.1038/s41401-018-0158-8

\section{INTRODUCTION}

Chemotherapy agents typically exert antitumor activity by producing reactive oxygen species (ROS) or free radicals. Unfortunately, these ROS are also responsible for serious side effects. A few antioxidant supplements, including melatonin, $\mathrm{N}$ acetylcysteine (NAC), vitamin $\mathrm{E}$, glutathione (GSH), $\beta$-carotene, and vitamin $C$, prevent oxidative damage caused by chemotherapy agents by combining free radicals and reducing ROS levels in organs [1, 2]. Ascorbic acid, a familiar antioxidant, has been shown to enhance the apoptotic effect of arsenic trioxide in acute myeloid leukemia (AML) $[2,3]$. Decades ago, nearly $70 \%$ of cancer patients took antioxidant supplements in combination with conventional chemotherapy [4]. However, the effects of antioxidant supplements on the efficacy of chemotherapeutic drugs remain unknown [5-7]. On the one hand, the use of antioxidant supplements during chemotherapy has been considered to counteract the actions of chemotherapeutic agents and subsequently decrease their antitumor activities [8]. On the other hand, antioxidant supplements have been considered useful because they allow patients to tolerate chemotherapy by alleviating toxic side effects, decrease multidrug resistance (MDR), and occasionally enhance chemotherapeutic drug efficacy [9-12].
Doxorubicin (DOX), an anthracycline anticancer drug, is widely used as a single agent or in combination with other cytotoxic drugs for the treatment of a variety of tumors, including lung, ovary, stomach, thyroid, bile ducts, esophagus, liver, and breast cancers, as well as osteosarcomas, soft-tissue sarcomas, and pediatric cancers $[13,14]$. However, the clinical use of DOX is severely limited due to dose-related adverse reactions and MDR after long-term treatment [15]. Cardiotoxicity or even congestive heart failure have been reported in the most serious cases of DOXinduced toxicity [16]. Increasing evidence has shown that patients suffer from liver injury with high-dose DOX treatments [17, 18]. ROS generation is viewed as one of the main mechanisms of anthracycline cytotoxicity. To counteract the harmful consequences of ROS generation, several types of pharmacologic agents, including antioxidants, hematopoietic cytokines, and iron-chelating agents, were used in conjunction with DOX during the course of treatment [18-20]. For example, oral supplementation with taurine zinc was found to attenuate DOX-induced hepatotoxicity and cardiotoxicity by elevating GSH biosynthesis, increasing superoxide dismutase activity, and attenuating malonaldehyde accumulation [21]. Thus, antioxidants may help minimize the toxic side effects of DOX.

\footnotetext{
${ }^{1}$ Key Lab of Drug Metabolism and Pharmacokinetics, State Key Laboratory of Natural Medicines, China Pharmaceutical University, 210009 Nanjing, China Correspondence: Guang-ji Wang (guangjiwang@hotmail.com) or Yan Liang (liangyan0679@hotmail.com)

These authors contributed equally: Bo-yu Shen and Chong Chen
}

Received: 6 June 2018 Accepted: 25 July 2018

Published online: 14 September 2018 
$\mathrm{GSH}$, a common endogenous antioxidant, plays a crucial role in protecting cells from oxidative damage [22, 23]. More than 25 years ago, GSH was used to improve the safety of DOX in clinical use. For example, a conjugate of DOX and GSH was found to play an important role in the induction of apoptosis by inhibiting glutathione S-transferase (GST) activity of rat hepatoma AH66 cells [24]. Current evidence has suggested that NAC, the source material for the synthesis of GSH, could reverse DOXinduced MDR by downregulating the over-expression of $\mathrm{P}$ glycoprotein caused by DOX [25]. However, much debate surrounding the use of antioxidants in cancer therapy has risen because antioxidants may weaken the cytotoxicity of DOX on tumor cells $[7,8,26]$. However, DOX kills cancer cells through multiple pathways, including via ceramide and ROS, free radical generation, cell membrane damage, and DNA cleavage by interacting with topoisomerase II [27]. Thus, the rationality for combining GSH and DOX has not been clear until now.

To gain a more robust understanding of the role that GSH plays in DOX-based chemotherapy, we investigated the dosedependent effects of GSH on the toxicity and efficacy of DOX from the pharmacokinetic and pharmacodynamic perspectives on both in vivo and in vitro models. The results demonstrated that exogenous GSH contributes to the prevention of acute myocardial and hepatic toxicity of DOX. However, exogenous GSH significantly attenuated the efficacy of DOX in a dose-dependent manner. Based on our findings, the combined use of DOX and GSH provides certain advantages and disadvantages. GSH should be exploited to attenuate DOX toxicity and prevented from counteracting DOX activity in clinical applications.

\section{MATERIALS AND METHODS}

Materials

DOX, Tris, L-serine, boric acid, and acivicin were purchased from Sigma-Aldrich (St. Louis, MO, USA). NAC was purchased from Jindu Co., Ltd (Shanghai, China). GSH (Lot. No. B141015) was kindly supplied by Kunming Jida Pharmaceutical Co., Ltd (Kunming, Yunnan, China). Captopril (CAP) and $N$-ethylmaleimide (NEM) standards were purchased from Sigma-Aldrich Corporation (St. Louis, MO, USA). Deionized water was prepared by a Milli-Q system (Millipore Corporation, Billerica, MA, USA).

\section{Animals}

All animal experiments were approved by the Ethical Committee of Animal Experiments of China Pharmaceutical University. BALB/C nude mice ( 5 weeks old, weighing 18-20 g) were purchased from Vital River Laboratory Animal Technology Co., Ltd (Beijing, China). All animals were housed in an environmentally controlled breeding room (temperature: $20-24^{\circ} \mathrm{C}$, humidity: $40-70 \%$, 12 -h dark/light cycle). They were fed with a standard laboratory mouse diet and provided with water. Prior to each experiment, all mice were fasted for $12 \mathrm{~h}$ with free access to water. Ethical procedures were conducted following the principles of reduction, replacement, and refinement (i.e., the $3 R^{\prime}$ 's rule).

The antitumor effects of combined therapy against a solid tumor model were assessed using male BALB/c nude mice. The mice were subcutaneously injected with $0.2 \mathrm{~mL}$ of $\mathrm{S} 180$ cell suspension $\left(1 \times 10^{7}\right.$ cells $)$ at the left axilla. Tumor-bearing mice were used when the volume of tumors reached $100-200 \mathrm{~mm}^{3}$. Tumor sizes and body weights were measured every 3 days during the experiment.

Cell culture

Rat cardiac myocytes ( $\mathrm{H} 9 \mathrm{c} 2$ ), human colon carcinoma cells (Caco-2), and human hepatocellular carcinoma cells (HepG2) were purchased from American Type Culture Collection (ATCC, Rockville, MD, USA), and cultured in Dulbecco's modified Eagle's medium containing
$10 \%$ fetal bovine serum $(\mathrm{FBS})$, penicillin $(100 \mathrm{U} / \mathrm{mL})$, and streptomycin $(100 \mathrm{U} / \mathrm{mL})$ at $37^{\circ} \mathrm{C}$ with $5 \% \mathrm{CO}_{2}$.

Human breast cancer cells (MCF-7) and human hepatocyte cells (HL7702) were obtained from the Institute of Hematology and Blood Diseases Hospital (Tianjin, China), and cultured in RPMI-1640 medium supplemented with $10 \% \mathrm{FBS}, 100 \mathrm{U} / \mathrm{mL}$ of penicillin, and $100 \mathrm{U} / \mathrm{mL}$ of streptomycin at $37^{\circ} \mathrm{C}$ with $5 \% \mathrm{CO}_{2}$.

Cardioprotective and hepatoprotective effects of GSH in Balb/c mice

The in vivo cardioprotective and hepatoprotective effects of GSH were evaluated using male Balb/c mice. The mice were weighed and randomly divided into seven groups with six animals each and treated as follows: Group 1: control group, intragastric (i.g.) administration of saline $(0.1 \mathrm{~mL} / 10 \mathrm{~g}$ per day) + intraperitoneal (i.p.) administration of saline (every other day); Group 2: model group, i.g. administration of saline $(0.1 \mathrm{~mL} / 10 \mathrm{~g}$ per day $)+$ i.p. administration of DOX ( $2 \mathrm{mg} / \mathrm{kg}$, every other day); Group 3: lowdose group, i.g. administration of GSH $(5 \mathrm{mg} / \mathrm{kg}$ per day $)+$ i.p. administration of DOX ( $2 \mathrm{mg} / \mathrm{kg}$, every other day); Group 4: medium-dose group, i.g. administration of GSH $(50 \mathrm{mg} / \mathrm{kg}$ per day) + i.p. administration of DOX ( $2 \mathrm{mg} / \mathrm{kg}$, every other day); Group 5: high-dose group, i.g. administration of GSH $(500 \mathrm{mg} / \mathrm{kg}$ per day) + i.p. administration of DOX ( $2 \mathrm{mg} / \mathrm{kg}$, every other day); Group 6: taurine (positive agent for cardioprotection) group, i.g. administration of taurine $(100 \mathrm{mg} / \mathrm{kg}$ per day) + i.p. administration of DOX ( $2 \mathrm{mg} / \mathrm{kg}$, every other day); Group 7: silymarin (positive agent for hepatoprotection) group, i.g. administration of silymarin $(100 \mathrm{mg} / \mathrm{kg}$ per day) + i.p. administration of DOX $(2 \mathrm{mg} / \mathrm{kg}$, every other day).

The treatment lasted for 2 weeks. DOX was injected i.p. into the mice in groups 2-7 every other day from days 1 to 15 until the total cumulative dosage reached $16 \mathrm{mg} / \mathrm{kg}$, while the mice in the control group were treated with an equal volume of saline. All mice were weighed every day to adjust the gavage volume. On the 15 th day, the mice were weighed and killed $2 \mathrm{~h}$ after DOX administration.

Echocardiographical analysis of cardiac function of Balb/c mice After the final treatment on the 15th day, the mice were fasted overnight, and then anesthetized with $2 \%$ isoflurane delivered via a nose cone. For the analysis of cardiac function, echocardiography was performed using a Vevo 770 system (VisualSonics, Toronto, Canada). The mouse heart was first imaged in B-mode in the parasternal long-axis view to examine the left ventricle (LV). To acquire accurate measurements of cardiac dimensions, M-mode images were obtained from long-axis and short-axis B-mode images by placing the M-mode sample gate perpendicular to the interventricular septum and LV walls at the level of papillary muscles. All M-mode measurements were performed during enddiastole $(-\mathrm{d})$ and end-systole $(-\mathrm{s})$ according to the leading-edge method of the American Society of Echocardiography. The LV structural parameters measured from the short-axis view in $M$ mode were used in the calculation of LV ejection fraction (LVEF).

Preparation of mouse blood, heart, and liver samples

Mouse blood, and heart and liver samples were collected after the echocardiographical analysis. Blood from the carotid aorta was collected into heparin-free tubes. The serum was separated by centrifugation at $2200 \times g$ for $10 \mathrm{~min}$ at $4{ }^{\circ} \mathrm{C}$ and subsequently stored at $-20^{\circ} \mathrm{C}$ before use. After blood collection, the mice were sacrificed by cervical dislocation under anesthesia. The heart and liver were immediately excised and washed with ice-cooled saline. All specimens were stored at $-80^{\circ} \mathrm{C}$ until analysis.

Measurement of brain natriuretic peptide

Mouse serum was collected to determine the concentration of brain natriuretic peptide (BNP) using an ELISA Kit (Invitrogen, 
Carlsbad, CA, USA) according to the manufacturer's instructions. The optical density of the final product was measured at $450 \mathrm{~nm}$ by a SynergyMx MBalb/coplate Reader (Biotek, USA).

Biochemical assays

The activities of serum alanine aminotransferase (ALT) and aspartate aminotransferase (AST) were measured by commercial kits purchased from Nanjing Jiancheng Bioengineering, Inc. (Nanjing, Jiangsu, China) strictly according to the manufacturer's instructions.

Antitumor effect of GSH in xenografted nude mice

The antitumor effects of combined therapy against a solid tumor model were assessed on xenografted nude mice. All xenografted mice were randomly assigned to five groups when the average tumor volume reached $100 \mathrm{~mm}^{3}$ ( $n=5$ in each group): Group 1: control group, i.g. administration of saline $(0.1 \mathrm{~mL} / 10 \mathrm{~g}$ per day $)+$ i.p. administration of saline (every other day); Group 2: model group, i.g. administration of saline $(0.1 \mathrm{~mL} / 10 \mathrm{~g}$ per day) + i.p. administration of DOX ( $2 \mathrm{mg} / \mathrm{kg}$ from days 1 to 7 , every other day); Group 3: low-dose group, i.g. administration of GSH $(5 \mathrm{mg} / \mathrm{kg}$ per day from days 1 to 7) + i.p. administration of DOX $(2 \mathrm{mg} / \mathrm{kg}$ from days 1 to 7, every other day); Group 4: medium-dose group, i. g. administration of GSH ( $5 \mathrm{mg} / \mathrm{kg}$ per day from days 1 to 7 ) + i.p. administration of DOX ( $2 \mathrm{mg} / \mathrm{kg}$ from days 1 to 7 , every other day); Group 5: high-dose group, i.g. administration of GSH $(5 \mathrm{mg} / \mathrm{kg}$ per day from days 1 to 7) + i.p. administration of DOX $(2 \mathrm{mg} / \mathrm{kg}$ from days 1 to 7 , every other day).

The tumor volume was measured every day by Vernier caliper to evaluate relative tumor growth ratio. All mice were executed and tumors were harvested. The samples were analyzed for tumor volume, relative tumor growth ratio, tumor inhibition ratio, DOX concentrations, and GSH concentrations in the tumor.

\section{Cell growth inhibition assay}

H9C2, HL7702, MCF-7, HepG2, and Caco-2 cells were seeded in 96well plates. When $90 \%$ confluent, the cells were incubated with 2 $\mu \mathrm{M}$ of DOX pretreated with control medium or NAC $(10 \mu \mathrm{M})$ for 2 h. Cell viability and proliferation were determined using CCK-8 assays. The assays were performed in five replicate wells and three parallel experiments for each sample.

\section{Cell apoptosis assay}

Apoptosis was measured by flow cytometry via dual Annexin VFITC/DAPI staining of MCF-7 cells. For the apoptosis assay, MCF-7 cells were seeded in 6-well plates. At approximately $90 \%$ confluence, the cells were pretreated with or without NAC for 2 $\mathrm{h}$ and then harvested after a $24 \mathrm{~h}$ treatment with DOX $(2 \mu \mathrm{M})$. Cell apoptosis assays were performed using Annexin V/DAPI iodide detection kits (Keygene, Nanjing, China) according to the manufacturer's instructions.

Cell migration assay

MCF-7 cells were seeded in 6-well plates. An artificial scratch "wound" was created with a $10-\mu \mathrm{L}$ pipette tip on confluent cell monolayers. Cells pretreated with or without NAC $(5 \mathrm{mM})$ in serum-free medium for $2 \mathrm{~h}$ were treated with DOX $(2 \mu \mathrm{M})$ for $24 \mathrm{~h}$. Disruption recovery was observed at 0,12 , and $24 \mathrm{~h}$. Each experiment was performed in triplicate at least three times.

\section{Quantitative analysis of DOX using the LC-MS/MS system}

First, mouse heart and liver tissues $(\sim 0.1 \mathrm{~g})$ were homogenized in $0.5 \mathrm{~mL}$ of $\mathrm{H}_{2} \mathrm{O}$ and protein-precipitated using a 5 -fold volume of methanol (containing $100 \mathrm{ng} / \mathrm{mL}$ azithromycin as an internal standard). Then, the samples were centrifuged at $30,000 \times g$ for 10 $\min$ at $4^{\circ} \mathrm{C}$. The supernatant was injected into a Finnigan TSQ LCMS/MS (liquid chromatography with tandem mass spectrometry) system (Thermo Electron, San Jose, CA, USA). A chromatographic separation was performed on a Luna $C_{18}$ column $\left(150 \times 2.0 \mathrm{~mm}^{2}\right.$, $5 \mathrm{~mm}$ ) (Phenomenex, Lake Forest, CA, USA). The mobile phase consisted of solvent $A$ (water containing $0.1 \%$ formic acid) and solvent $B$ (methanol) with the following gradient: 0 min, $20 \% \mathrm{~B} \rightarrow$ $0.5 \mathrm{~min}, 20 \% \mathrm{~B} \rightarrow 0.8 \mathrm{~min}, 80 \% \mathrm{~B} \rightarrow 4 \mathrm{~min}, 80 \% \mathrm{~B} \rightarrow 5.5 \mathrm{~min}, 20 \%$ $B \rightarrow 8 \mathrm{~min}, 20 \% \mathrm{~B}$. The flow rate was $0.2 \mathrm{~mL} / \mathrm{min}$. The $\mathrm{MS}$ parameters were as follows: spray voltage was $4.8 \mathrm{kV}$, sheath gas pressure was $42 \times 10^{5} \mathrm{~Pa}$, auxiliary gas pressure was $6 \times 10^{5} \mathrm{~Pa}$, and ion transfer capillary temperature was $285^{\circ} \mathrm{C}$. The multiple reaction monitoring (MRM) transitions were as follows: $\mathrm{m} / \mathrm{z}$ $544.7 \rightarrow 361.0$ (DOX), $\mathrm{m} / \mathrm{z} 749.7 \rightarrow 591.4$ (azithromycin, internal standard)

Quantitative analysis of GSH using the LC-MS/MS system Three steps were followed in the purification of GSH in mouse heart and liver: (i) preparing tissue homogenization: the mouse heart and liver were collected, quickly washed with cold saline, and homogenized in a 5 -fold volume of homogenization buffer $(6 \mathrm{mg} / \mathrm{mL}$ of Tris, $1.24 \mathrm{mg} / \mathrm{mL}$ of boric acid, $0.2 \mathrm{mg} / \mathrm{mL}$ of serine, $4 \mu \mathrm{g} / \mathrm{mL}$ of acivicin, and $7.76 \mathrm{mg} / \mathrm{mL}$ of $\mathrm{NEM}, \mathrm{pH}=8$ ); (ii) derivatization of GSH: $10 \mu \mathrm{L}$ of internal standard solution $(5 \mu \mathrm{g} /$ $\mathrm{mL}$ of (AP-NEM) were added into the tissue homogenization, and derivation was conducted for $1 \mathrm{~h}$; (iii) protein precipitation in the tissue homogenization: methanol (5-fold volume) was added to the homogenization. After vortex-mixing for $1 \mathrm{~min}$, the mixture was centrifuged at $30,000 \times g$ for $10 \mathrm{~min}$. An aliquot of $5 \mu \mathrm{L}$ supernatant was analyzed by LC-MS/MS (LC-MS/MS 4000 system, SCIEX, MA, USA).

Chromatographic separation was achieved on a Sepax Bio-ODS SP column $\left(4.6 \times 150 \mathrm{~mm}^{2}, 5 \mu \mathrm{m}, \mathrm{GL}\right.$ Sciences Inc., Japan) under a gradient program. The mobile phase consisted of solvent $A\left(\mathrm{H}_{2} \mathrm{O}\right.$ containing $0.1 \%$ formic acid and $2 \mathrm{mM}$ ammonium formate) and solvent $B$ (methanol). The elution program was as follows: 0 min, $10 \% \mathrm{~B} \rightarrow 0.2 \mathrm{~min}, 10 \% \mathrm{~B} \rightarrow 0.4 \mathrm{~min}, 50 \% \mathrm{~B} \rightarrow 4 \mathrm{~min}, 50 \% \mathrm{~B} \rightarrow 4.5$ $\min , 10 \% \mathrm{~B} \rightarrow 6 \mathrm{~min}, 10 \% \mathrm{~B}$. The optimized MS parameters were as follows: ion spray voltage, $5000 \mathrm{~V}$; ion source gas 1,60 ; ion source gas 50; curtain gas, 10 ; collision gas, 6 ; source temperature, $550^{\circ} \mathrm{C}$. The MRM transitions were as follows: $\mathrm{m} / \mathrm{z} 433.1 \rightarrow 304.1$ (GSHNEM), $m / z 343.1 \rightarrow 228.1$ (CAP-NEM, internal standard).

Quantification of intracellular concentrations of GSH and DOX MCF-7 cells were seeded in 12-well plates. At approximately $90 \%$ confluence, the cultured cells were pretreated with control medium or NAC $(10 \mu \mathrm{M})$ for $2 \mathrm{~h}$, treated with DOX $(5 \mu \mathrm{M})$ for a designated period of time $(0.5,1,2$, and $4 \mathrm{~h})$, and subsequently collected. The concentrations of intracellular GSH and DOX were determined by LC-MS/MS.

Statistical analysis

Statistical analyses were performed with the Prism software (version 6.0c). All data are presented as the mean \pm standard deviations (SD). Arithmetic means were compared using twotailed $t$ tests. $P<0.05$ were considered statistically significant.

\section{RESULTS}

GSH alleviates DOX-induced cardiotoxicity

The LVEF was measured to investigate the influence of GSH on DOX-induced cardiotoxicity. As shown in Fig. 1a, the LVEF significantly decreased from $66.20 \pm 4.83$ to $39.14 \pm 3.09$ after a multi-dose administration of DOX $(P<0.01)$. Combined treatment with GSH $(5,50$, and $500 \mathrm{mg} / \mathrm{kg}$ per day, i.g.) significantly attenuated the down-regulated LVEF levels caused by DOX. BNP, a biomarker of cardiac disease, was determined to further elucidate the protective effects of GSH on DOX-induced cardiotoxicity. Clearly, the multi-dose administration of DOX significantly enhanced BNP levels in the mouse heart, and the combined use of GSH markedly decreased the high BNP levels caused by DOX 
a

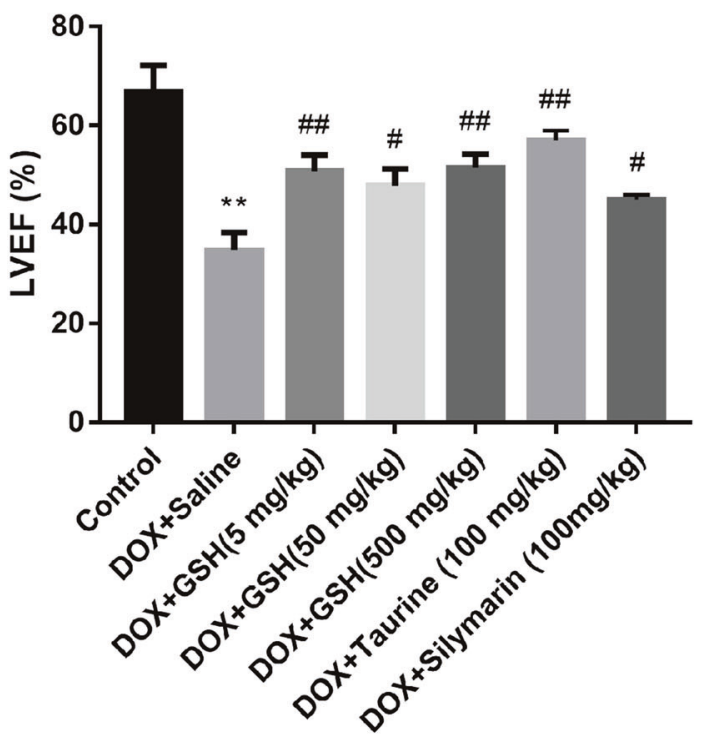

b

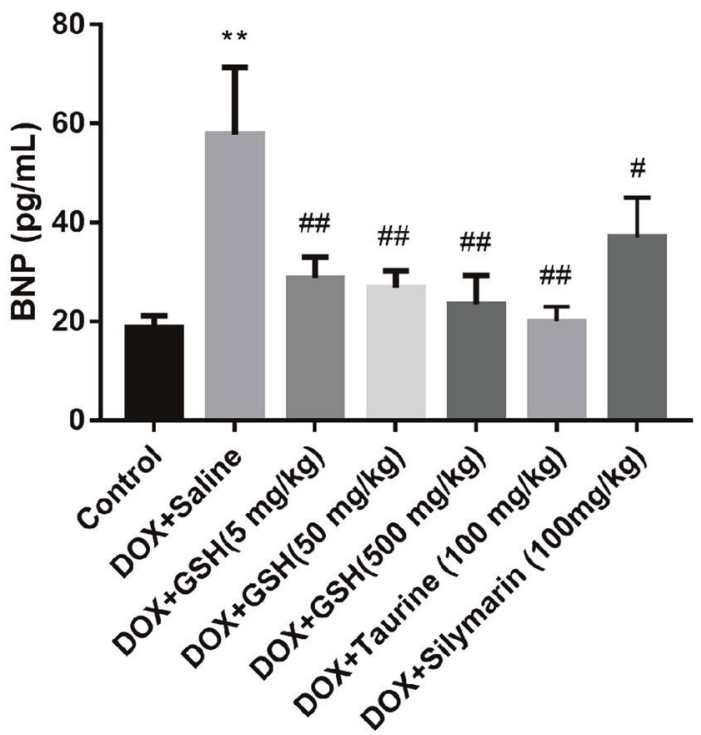

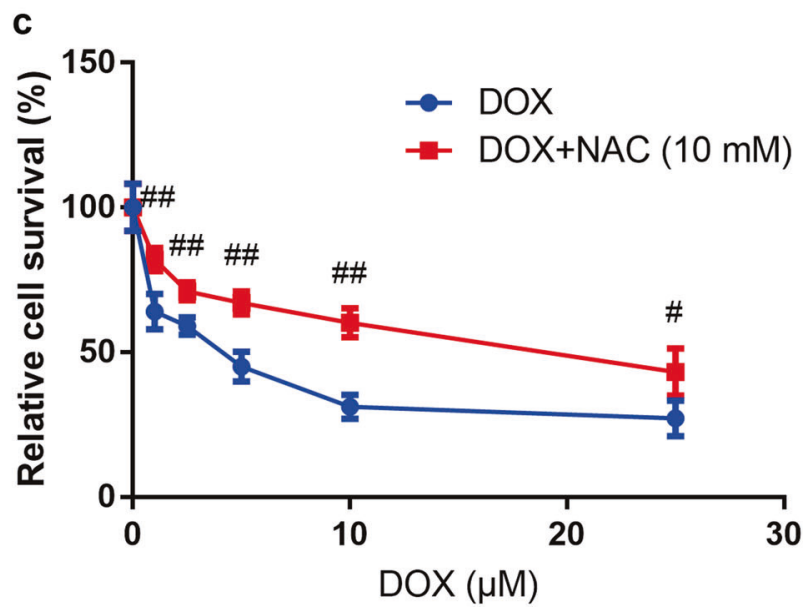

Fig. 1 The effect of GSH on the DOX-induced cardiotoxicity. a Left ventricle ejection fraction (LVEF) levels. b Brain natriuretic peptide (BNP) levels. c Relative survival of $\mathrm{H} 9 \mathrm{c} 2$ cardiac muscle cells. Mean \pm SD. $n=3$. ${ }^{* *} P<0.01$ vs. control group; ${ }^{\#} P<0.05,{ }^{\# \#} P<0.01$ vs. DOX + saline group

(Fig. 1b). The protective function of GSH toward H9c2 cardiac muscle cell damage induced by DOX was also investigated. Results from CCK-8 detection assays showed that increasing DOX concentration from 1 to $25 \mu \mathrm{M}$ reduced the survival rate of $\mathrm{H} 9 \mathrm{c} 2$ cells. Pretreatment with NAC $(10 \mathrm{mM})$ for $2 \mathrm{~h}$, that is, a source of $\mathrm{GSH}$, greatly enhance the survival rate of the H9c2 cells (Fig. 1c).

GSH alleviates DOX-induced hepatotoxicity

ALT and AST activities were measured to investigate the influence of GSH on DOX-induced hepatotoxicity. As shown in Fig. 2a, serum ALT activity was significantly enhanced by multi-dose administration of DOX $(P<0.001)$. Combined treatment with GSH $(5,50$, and $5000 \mathrm{mg} / \mathrm{kg}$ per day, i.g.) greatly attenuated the elevation of serum ALT activity caused by DOX. Similarly, serum AST activity was significantly enhanced by DOX, and the combined use of GSH dramatically decreased the high serum AST activity caused by DOX (Fig. 2b). The effect of GSH on DOX-induced hepatotoxicity was investigated on HL7702 cells. Results from CCK-8 detection assays showed that DOX $(1,2,5,10$, and $25 \mu \mathrm{M})$ concentrationdependently reduced the survival rate of the HL7702 cells. Pretreatment with $10 \mathrm{mM}$ of NAC greatly increased the survival rate of the HL7702 cells (Fig. 2c).
Increased GSH has no effect on targeted distribution of DOX in hearts and livers of mice

To investigate the effect of GSH on the targeted distribution of DOX, the concentrations of GSH and DOX in mouse heart and liver were determined. As shown in Fig. 3a, DOX treatment did not significantly decrease GSH levels in mouse heart; the concentrations of GSH in the DOX group were $5.99 \pm 0.40 \mu \mathrm{g} / \mathrm{g}$ heart. The combined use of GSH at 50 and $500 \mathrm{mg} / \mathrm{kg}$ with DOX enhanced the GSH levels to $9.76 \pm 1.37$ and $10.82 \pm 1.30 \mu \mathrm{g} / \mathrm{g}$ heart, respectively. The concentrations of DOX in mouse hearts are shown in Fig. 3b. After i.p. administration of DOX, the concentrations of DOX were $53.96 \pm 3.12 \mu \mathrm{g} / \mathrm{g}$ heart. The concentrations of DOX in the DOX+ GSH $(5 \mathrm{mg} / \mathrm{kg}), \mathrm{DOX}+\mathrm{GSH}(50 \mathrm{mg} / \mathrm{kg})$, and $\mathrm{DOX}+\mathrm{GSH}(500 \mathrm{mg} / \mathrm{kg})$ groups were $45.30 \pm 6.80,60.02 \pm 2.94$, and $59.56 \pm 9.72 \mu \mathrm{g} / \mathrm{g}$ heart, respectively. Thus, the combined use of GSH and DOX had no obvious influence on the concentration of DOX in mouse heart. In mouse liver, DOX decreased GSH from $9.91 \pm 0.60$ to $6.86 \pm 0.34 \mu \mathrm{g} / \mathrm{g}$ liver. The combined use of GSH at 50 and $500 \mathrm{mg} / \mathrm{kg}$ with DOX restored GSH levels to $10.09 \pm 0.83$ and $10.68 \pm 0.68 \mu \mathrm{g} / \mathrm{g}$ liver (Fig. 3c). However, as illustrated in Fig. 3d, increased GSH levels had no obvious effect on the exposure of DOX in mouse liver. 
a

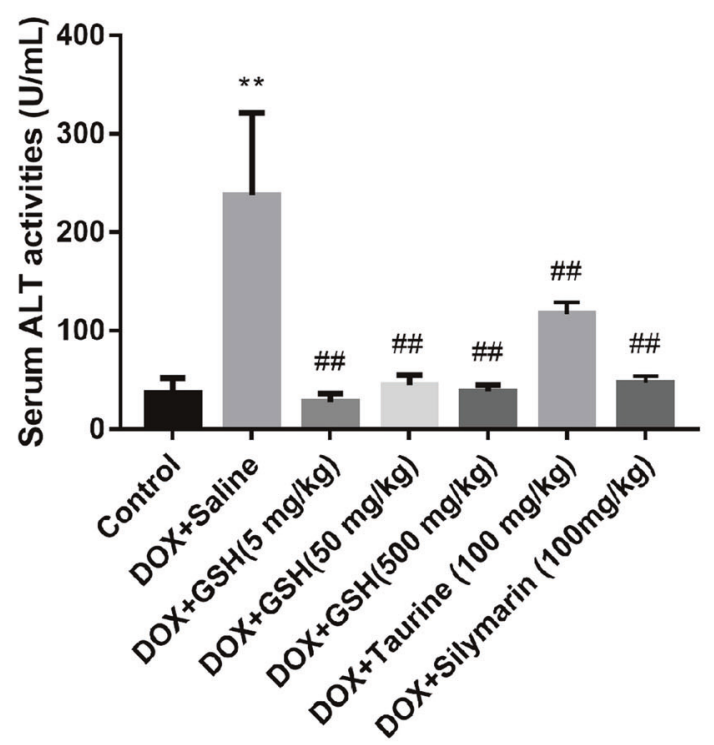

b

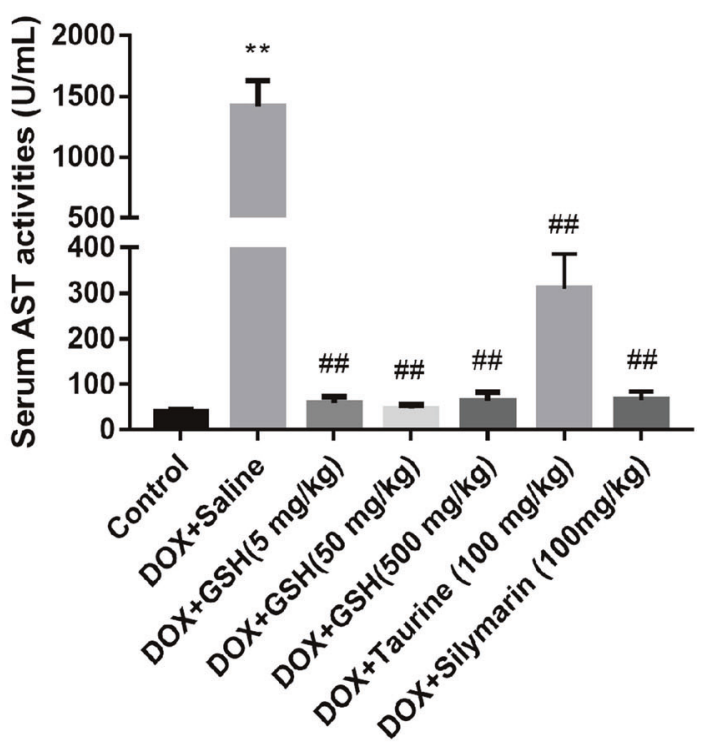

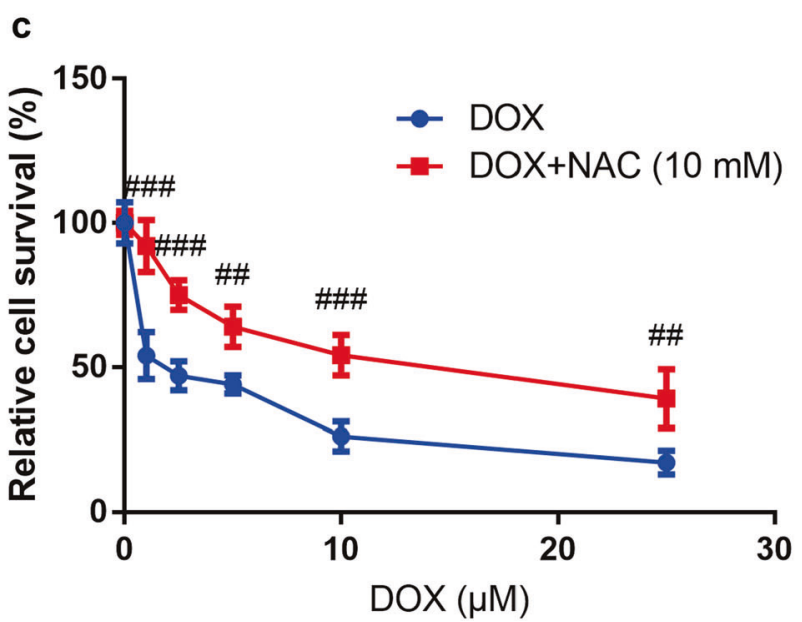

Fig. 2 The effect of GSH on the DOX-induced hepatotoxicity. a Serum ALT activities. b Serum AST activities. c Relative survival of HL7702 cardiac muscle cells. Mean \pm SD. $n=3$. ${ }^{* *} P<0.01$ vs. control group; ${ }^{\# \#} P<0.01,{ }^{\# \# \#} P<0.001$ vs. DOX + saline group

GSH attenuates antitumor efficacy of DOX in nude mouse model The influence of GSH on the antitumor efficacy of DOX was investigated by measuring solid tumor volume and relative tumor growth ratio. As shown in Fig. 4a, b, DOX treatment significantly suppressed tumor growth, and the tumor inhibitory ratio of DOX was more than $90 \%$. The combined use of GSH dose-dependently attenuated the antitumor efficacy of DOX. Tumor growth curves of the DOX, DOX + low-dose GSH (5 mg/kg), DOX + medium-dose GSH $(50 \mathrm{mg} / \mathrm{kg})$, and DOX + high-dose GSH $(500 \mathrm{mg} / \mathrm{kg})$ groups clearly showed that the combined use of GSH from the first day to the seventh day significantly decreased the antitumor efficacy of DOX (Fig. 4c).

Increased GSH has no effect on targeted distribution of DOX in tumors of nude mice

To investigate the effect of GSH on the targeted distribution of DOX, the concentrations of GSH and DOX in mouse tumors were quantitatively analyzed. As shown in Fig. $4 d$, the concentrations of GSH in the control group were $4.39 \pm 1.15 \mu \mathrm{g} / \mathrm{g}$ tumor. DOX treatment significantly decreased the GSH levels in mouse tumors, and the GSH concentration in the DOX group was $0.60 \pm 0.15 \mu \mathrm{g} / \mathrm{g}$ tumor. The combined use of GSH at 5,50 , and $500 \mathrm{mg} / \mathrm{kg}$ with
DOX enhanced GSH levels to $1.76 \pm 0.73,2.00 \pm 0.34$, and $2.23 \pm$ $0.44 \mu \mathrm{g} / \mathrm{g}$ tumor, respectively. The concentrations of DOX in mouse tumors are illustrated in Fig. 4e. After i.p. administration of DOX at a dose of $2 \mathrm{mg} / \mathrm{kg}$, the concentrations of DOX were $1.53 \pm$ $0.72 \mu \mathrm{g} / \mathrm{g}$ tumor. The concentrations of DOX in the DOX $+\mathrm{GSH}(5$ $\mathrm{mg} / \mathrm{kg}), \mathrm{DOX}+\mathrm{GSH}(50 \mathrm{mg} / \mathrm{kg})$, and DOX $+\mathrm{GSH}(500 \mathrm{mg} / \mathrm{kg})$ groups were $1.65 \pm 0.54,1.72 \pm 0.35$, and $1.54 \pm 0.38 \mu \mathrm{g} / \mathrm{g}$ tumor, respectively. Thus, the combined use of GSH with DOX had no obvious influence on the concentration of DOX in tumors.

GSH attenuates antitumor efficacy of DOX in tumor cell lines Three types of tumor cell lines (Caco-2, HepG2, and Mcf-7) were cultured and used to investigate the effect of GSH on the antitumor efficacy of DOX. The results from the CCK- 8 detection assays showed that $\operatorname{DOX}(0.25,0.5,1.0,2.5$, and $5 \mu \mathrm{M})$ dosedependently reduced the survival rates of Caco-2 and HepG2 cells. Furthermore, co-incubation of NAC $(10 \mathrm{mM})$ greatly attenuated the inhibition efficacy of DOX on these cancer cells (Fig. $5 a, b$ ). In MCF-7 cells, $0.1,0.25,0.5,1$, and $2.5 \mu \mathrm{M}$ of DOX also inhibited the survival rate in a dose-dependent manner. The inhibition efficacy of DOX was significantly reduced by treatment with $10 \mathrm{mM}$ of NAC (Fig. 5c). 
a

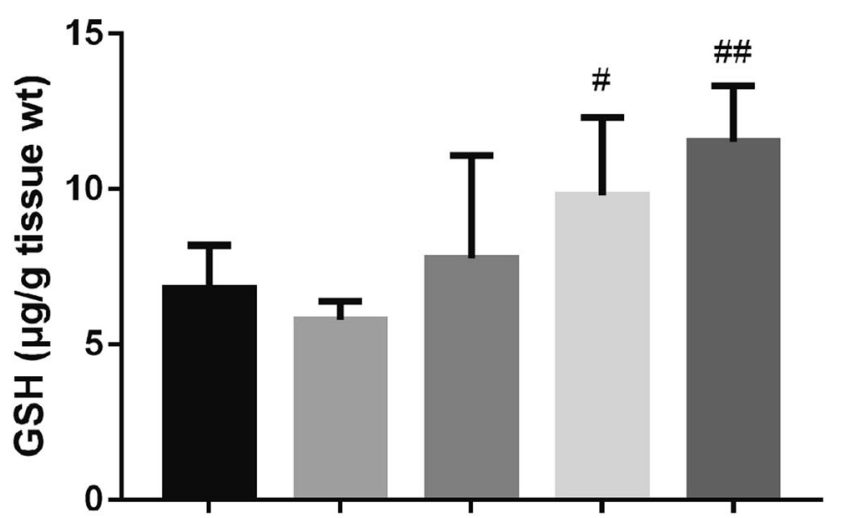

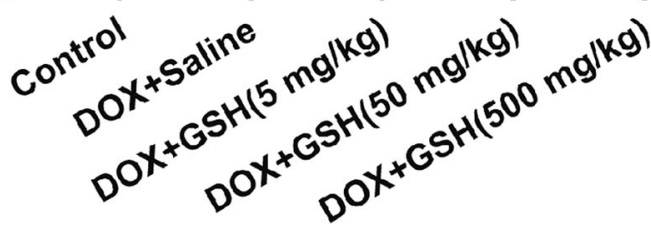

C

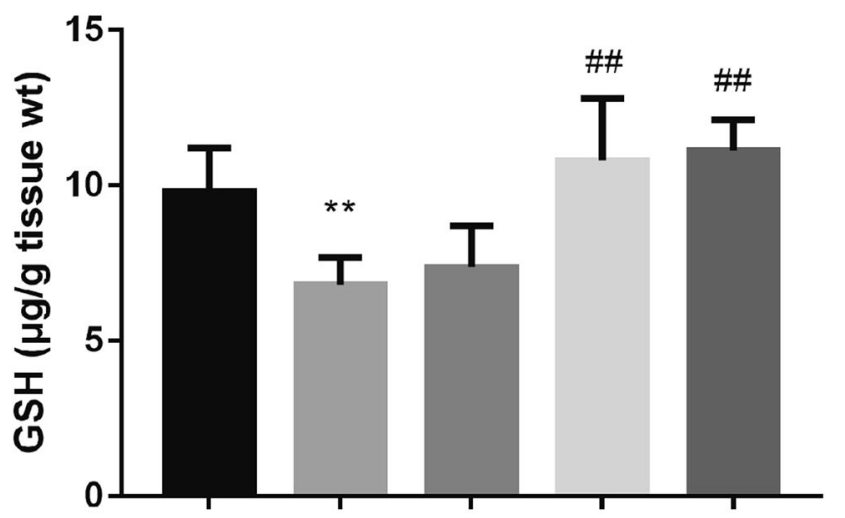

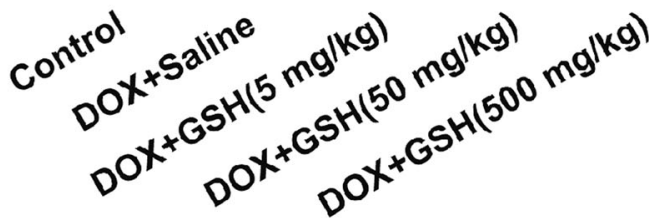

b

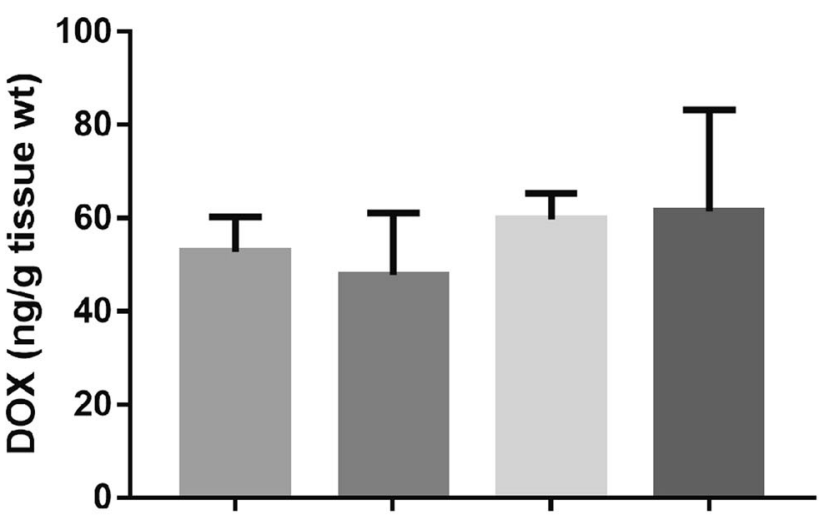

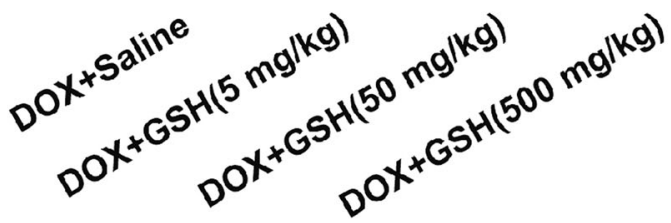

d
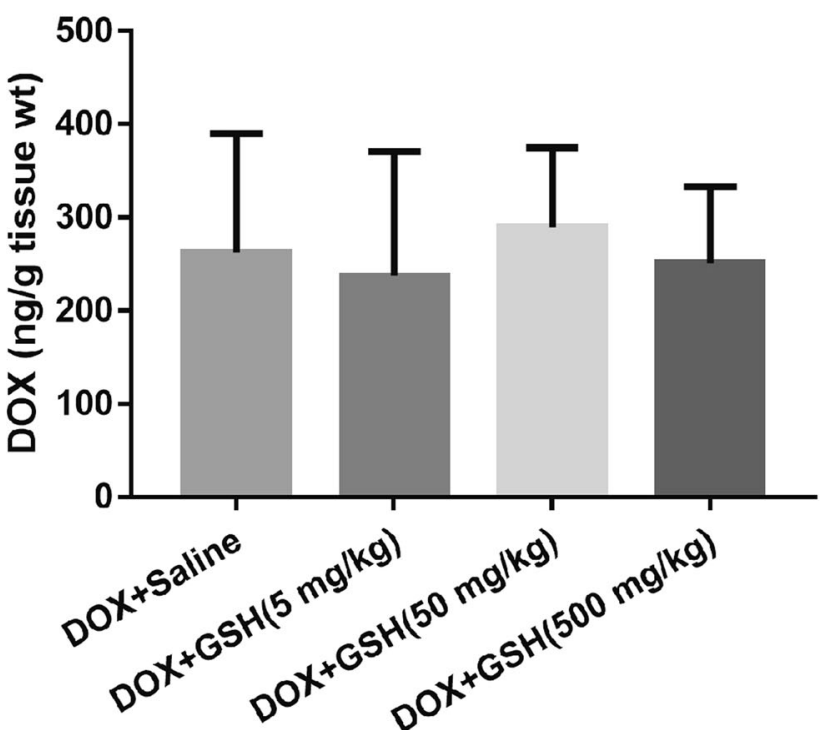

Fig. 3 Pharmacokinetic drug-drug interactions of GSH and DOX in mouse heart and liver. a Effects of DOX on the concentrations of GSH in mouse heart. $\mathbf{b}$ Effects of GSH on the concentrations of DOX in mouse heart. $\mathbf{c}$ Effects of DOX on the concentrations of GSH in mouse liver. d Effects of GSH on the concentrations of DOX in mouse liver. Mean \pm SD. $n=3$. ${ }^{* *} P<0.01$ vs. control group; ${ }^{\#} P<0.05,{ }^{\# \#} P<0.01$ vs. DOX + saline group

A wound healing assay using MCF-7 cells was conducted to investigate the influence of GSH and DOX on cell migration. In the control group, the wound width in the MCF-7 monolayer at $24 \mathrm{~h}$ was much smaller than that at $0 \mathrm{~h}$ (Fig. $5 \mathrm{~d}$ ). DOX (5 $\mu \mathrm{M})$ efficiently prevented the migration of the MCF-7 cells. After combining treatment with NAC $(400 \mu \mathrm{M}, 2 \mathrm{mM}$, and $10 \mathrm{mM})$, the wound width in the MCF-7 layer at $24 \mathrm{~h}$ was clearly smaller than that in the DOX group; NAC attenuated the inhibition efficacy of DOX in a dosedependent manner.

Additionally, cell apoptosis was determined by Annexin V-FITC/ DAPI double staining method to further investigate the influence of GSH on the antitumor efficacy of DOX. In the apoptosis scheme in Fig. 6a-e, Q1-UR indicates late apoptosis and necrosis, Q1-LL represents live cells, and Q1-LR represents early apoptotic cells. Clearly, DOX induced significant increases in late apoptosis and necrosis of MCF-7 cells at $24 \mathrm{~h}$, and the live cell percentage decreased from $96.2 \%$ (control group) to $32.3 \%$. After pretreatment with $400 \mu \mathrm{M}$ of NAC, the live cell percentage increased to $58.1 \%$ (Fig. $6 \mathrm{c}$ ). Furthermore, $2 \mathrm{mM}$ and $10 \mathrm{mM}$ of NAC increased the live cell percentage to $63.8 \%$ and $64.9 \%$, respectively (Fig. $6 \mathrm{~d}, \mathrm{f}$ ).

Increased GSH has no effect on the uptake of DOX in tumor cell lines

NAC, the pro-drug for the synthesis of GSH, supposedly enhances intracellular GSH levels [4, 19]. Herein, the GSH concentrations in control, DOX-treated, DOX + NAC-treated $(400 \mu \mathrm{M})$, DOX + NACtreated $(2 \mathrm{mM})$, and DOX + NAC-treated $(10 \mathrm{mM}) \mathrm{MCF}-7$ cells were quantitatively analyzed using LC-MS/MS. As shown in Fig. 7a, the GSH concentration levels in MCF-7 cells decreased with $2 \mu \mathrm{M}$ DOX treatment and with increasing incubation time. However, the 
a

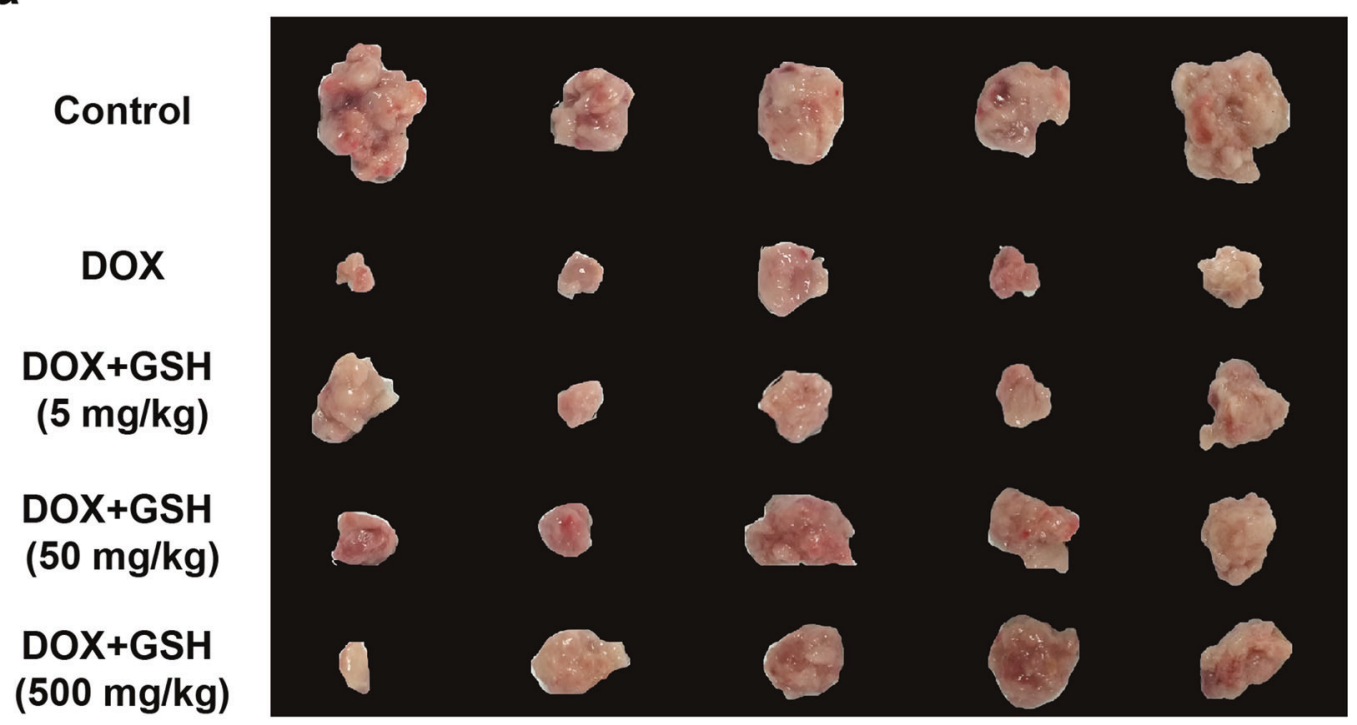

b

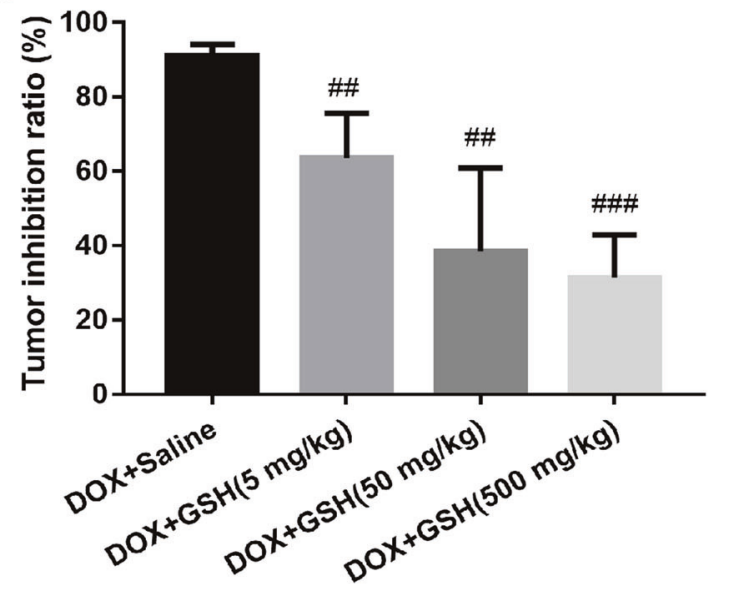

d

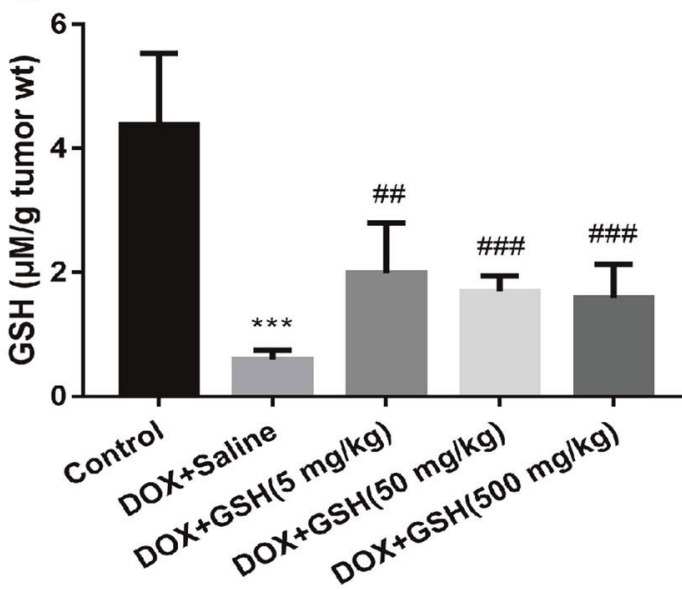

C

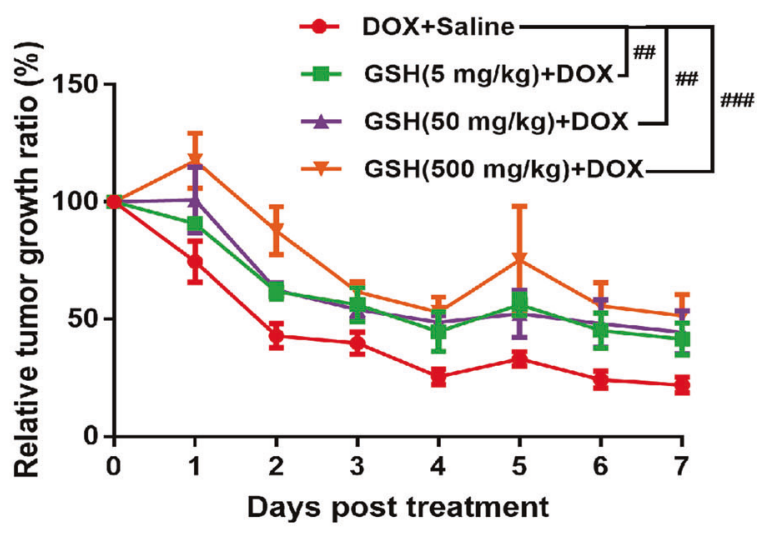

e

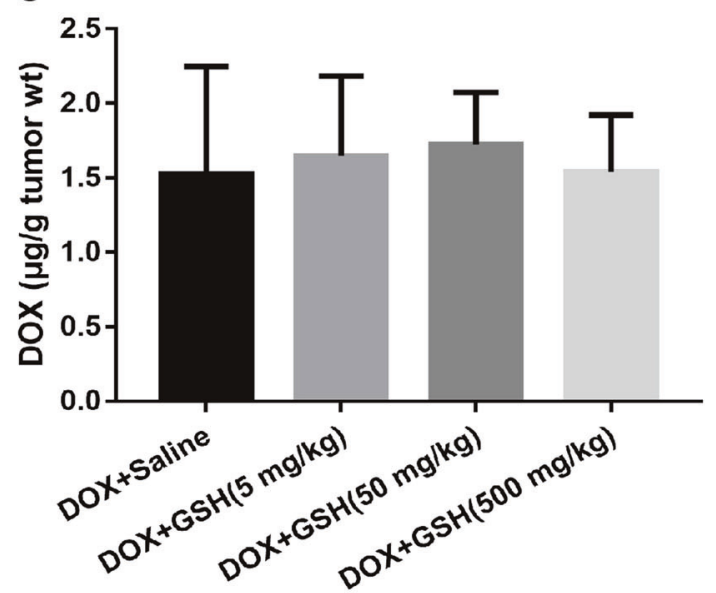

Fig. 4 The influence of GSH on the antitumor efficacy of DOX, and the pharmacokinetic drug-drug interactions of GSH and DOX in mouse tumor. a Tumor photos, $\mathbf{b}$ tumor inhibition rate, and $\mathbf{c}$ relative tumor growth ration (\%). d Effects of DOX on the concentrations of GSH in mouse tumor. e The effect of GSH on the concentrations of DOX in mouse tumor. Mean \pm SD. $n=3$. ${ }^{* * *} P<0.001$ vs. control group; ${ }^{\# \#} P<0.01$, $\# \# P<0.001$ vs. DOX + saline group 
a

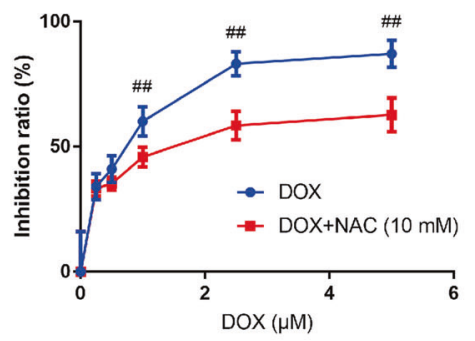

b

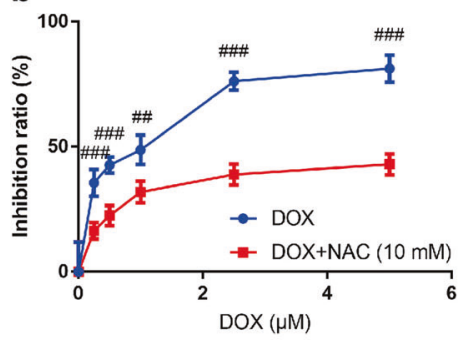

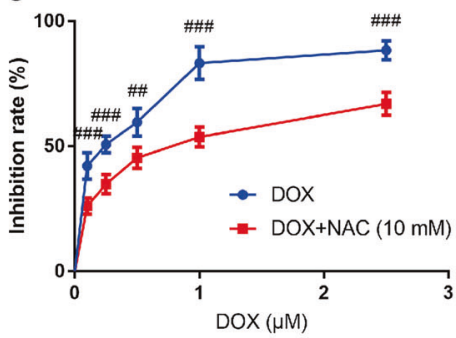

d

$\mathrm{Oh}$
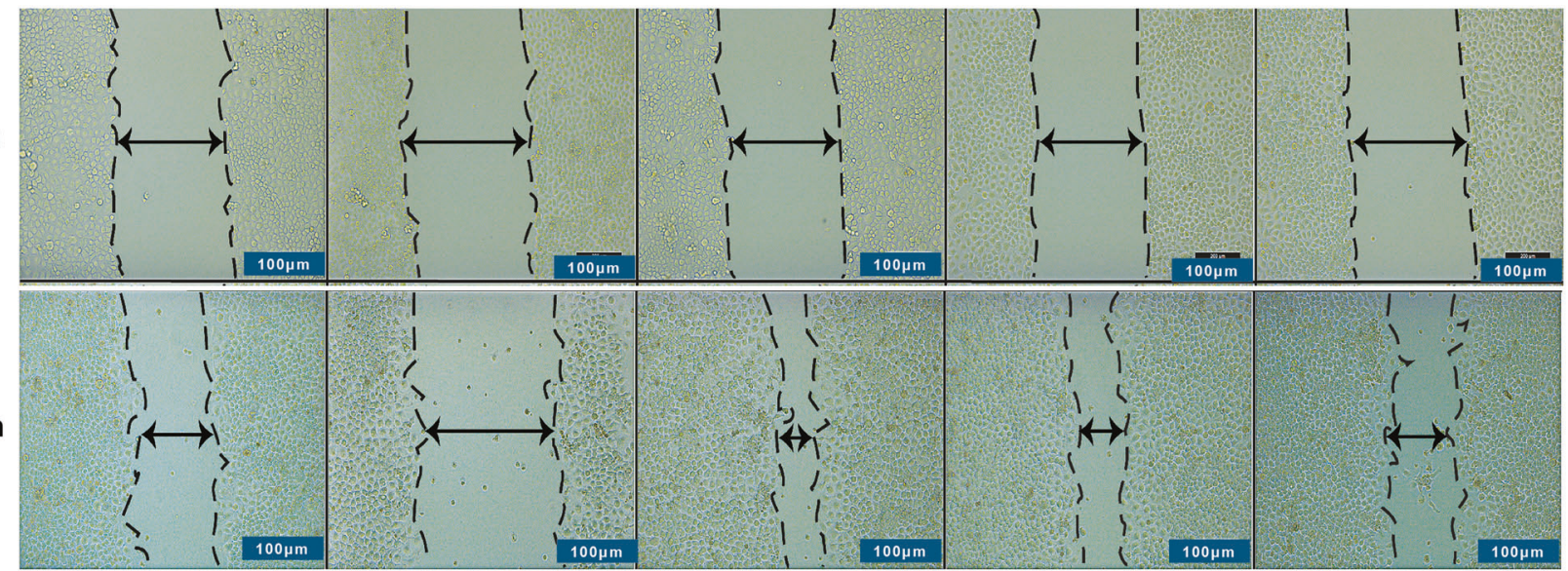

Control

DOX alone

DOX+NAC (10 mM)

DOX+NAC (2 mM)

Fig. 5 The influence of GSH on the antitumor efficacy of DOX in cancer cells. a Survival rates of Caco-2 cells. b Survival rates of HepG2 cells. c Survival rates of MCF-7 cells. $\mathbf{d}$ Influence of GSH and DOX on the MCF-7 cell migration. Mean \pm SD. $n=3$. ${ }^{\# \#} P<0.01, \# \# \#<0.001$ vs. DOX group

combined treatment with NAC significantly enhanced GSH concentrations in MCF-7 cells $(P<0.01)$. Additionally, the effect of GSH on the uptake of DOX in MCF-7 cells was determined. The results suggested that the combined treatment with NAC had no obvious influence on the exposure levels of DOX in MCF-7 cells (Fig. 7b).

\section{DISCUSSION}

The clinical application of antioxidants during conventional cancer treatment is among one of the most controversial areas in oncology. Some supporters have observed a relationship between the enhanced intake of antioxidants and a declined risk of producing lung, esophageal, and gastrointestinal cancers [28-31]. During the past decade, ascorbic acid, a familiar antioxidant, has been shown to enhance the apoptotic effect of arsenic trioxide $\left(\mathrm{As}_{2} \mathrm{O}_{3}\right)$ on $\mathrm{AML}$ cells and various clinical samples of AML. This suggests a possible combined $\mathrm{As}_{2} \mathrm{O}_{3}$ /ascorbic acid therapy in patients with $\mathrm{AML}[2,3]$. However, increasing evidence indicates that antioxidants may weaken the antitumor activity of chemotherapeutic agents $[7,8,26]$. Although the combined use of antioxidants and chemotherapeutic agents has been explored for more than 20 years, the duration, administration route, and type of antioxidant that may elicit interactive effects have not been established until now.

DOX, one of the most effective antitumor agents, has been included in standard chemotherapy protocols for breast cancer since first used decades ago $[32,33]$. However, the clinical use of DOX has been restricted by dose-dependent toxicity (myelosuppression and cardiotoxicity), narrow therapeutic ranges, MDR, and low specificity against cancer cells $[22,25]$. Several reports suggest that DOX can initiate a reaction cascade leading to oxygen free radical generation in the myocardium and result in extensive peroxidative damage [34-37]. The oxidative stress hypothesis of DOX-induced cardiotoxicity is based on a series of studies on transgenic mice [38]. GSH, a common endogenous antioxidant, plays a crucial role in protecting cells from oxidative damage. In 1986, Yoda et al. [22], reported that i.p. administration of exogenous GSH $(500 \mathrm{mg} / \mathrm{kg})$ protected heart muscles from DOX toxicity without reducing the antitumor effects of DOX. In 1990, Villani et al. [23], investigated that the effects of GSH and NAC (a ROS scavenger) on DOX-induced cardiotoxicity for in vitro and in vivo models. The results showed that GSH significantly prevented negative inotropic effects produced by DOX in the DOX-treated animals and isolated rat atria [23]. Furthermore, antioxidants have been shown to increase the effectiveness of cytotoxic therapy $[7,25,39-41]$. The combined use of DOX and GSH seems to be beneficial in the clinical application of DOX. However, antioxidants have also been considered to diminish the effects of conventional cytotoxic therapies $[7,8,26]$. In the present study, the rationality for the combined use of DOX and GSH was systematically investigated by exploring the effects of GSH on the toxicity and efficacy of DOX. Pharmacokinetic and pharmacodynamic approaches were used for in vivo and in vitro models.

Cardiac toxicity is the main side effect of DOX. The cardioprotective effects of GSH against DOX-induced heart injury were studied with in vivo (Balb/c mice) and in vitro (H9c2 cells) models. As shown in Fig. 1, the LVEF and BNP in DOX-induced heart injury mice were significantly improved by the combined DOX treatment with GSH (i.g. 5, 50, and $500 \mathrm{mg} / \mathrm{kg}$ per day). Additionally, GSH was found to apparently reverse $\mathrm{H} 9 \mathrm{c} 2$ cell apoptosis caused by DOX. As shown in Fig. 3c, the combined uses of DOX with GSH at 5, 50, and $500 \mathrm{mg} / \mathrm{kg}$ had no obvious influences on the distribution of DOX but did enhance GSH concentrations in mouse heart. In addition to these cardioprotective effects, hepatoprotective effects of GSH against DOX-induced liver injury were studied with 
a

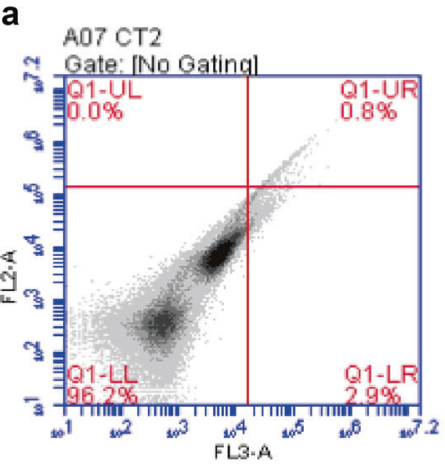

Control

d

$\mathrm{B} 01 \mathrm{M} 2$

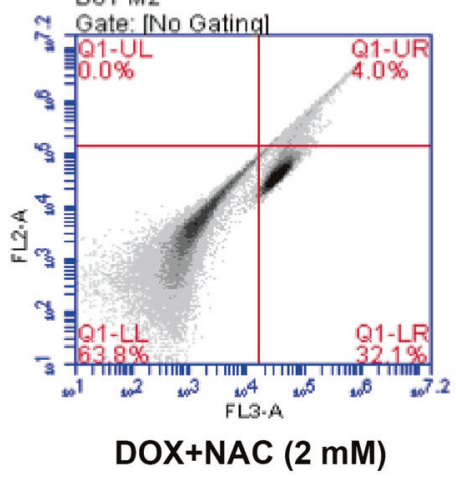

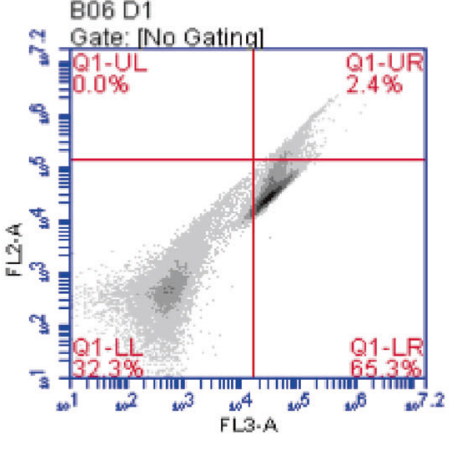

DOX alone

e

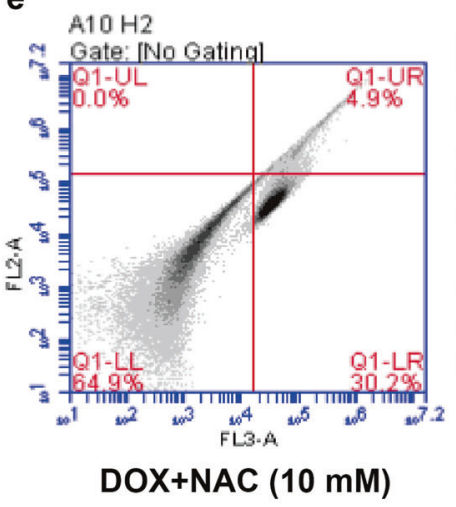

C

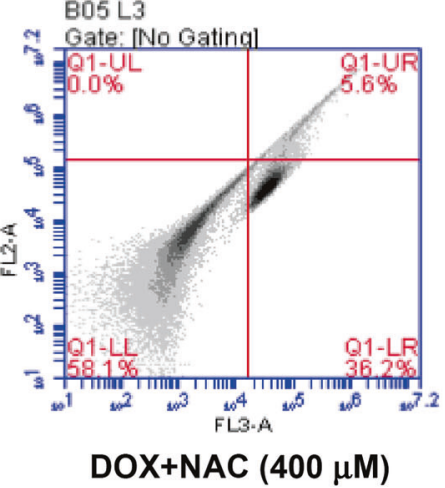

f

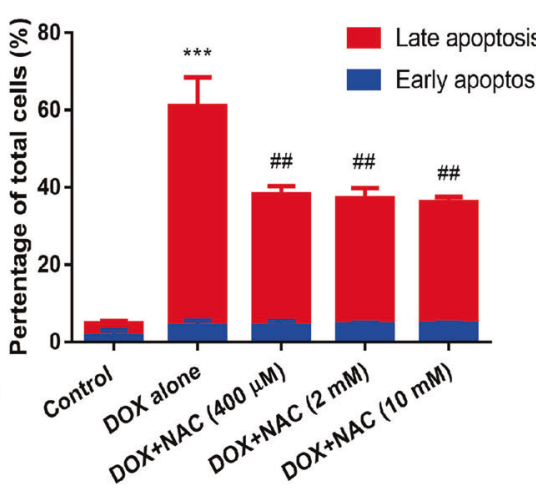

Fig. 6 Influence of GSH on the MCF-7 cell apoptosis. a Control group, b DOX-treated group, c DOX + NAC (400 $\mu$ M) group, d DOX + NAC (2 $\mathrm{mM})$ group, e DOX + NAC $(10 \mathrm{mM})$ group, and $\mathbf{f}$ percentage of late apoptosis and early apoptosis. Mean \pm SD. $n=3$. ${ }^{* * *} P<0.001$ vs. control group; ${ }^{\# \#} P<0.01$ vs. DOX-alone group
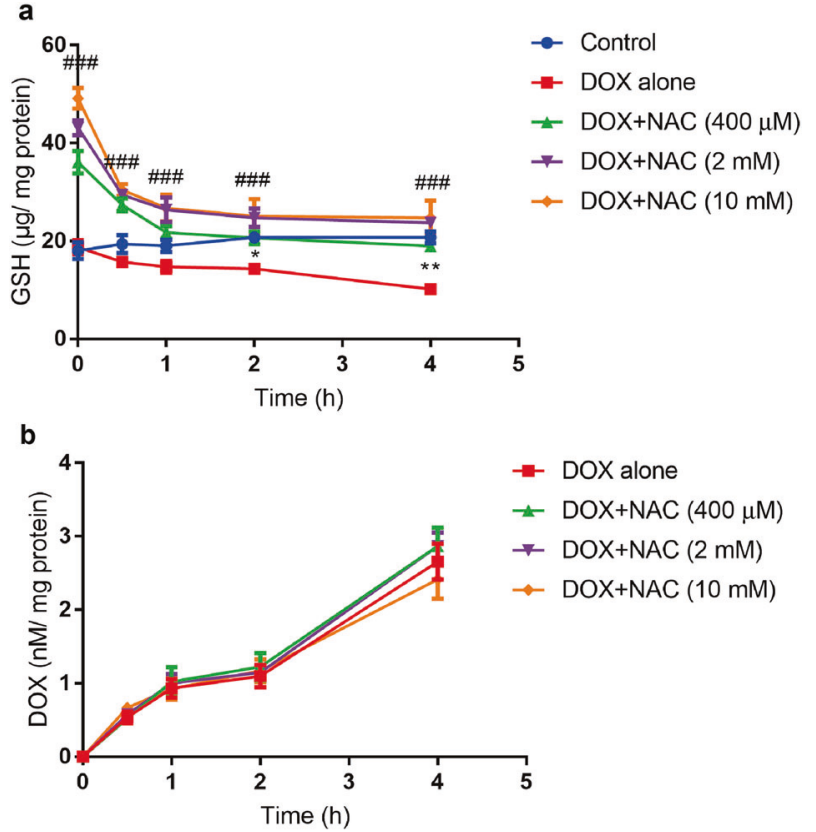

Fig. 7 The uptake interaction of GSH and DOX in MCF-7 cell lines. a Effects of DOX on the uptake of GSH. b Effects of GSF on the uptake of DOX. Mean \pm SD. $n=3 .{ }^{*} P<0.05,{ }^{* *} P<0.01$ vs. control group; ${ }^{\# \# \#} P$ $<0.001$ vs. DOX-alone group in vivo (Balb/c mice) and in vitro (HL7702) models. In the in vivo mouse model, the activities of serum ALT and AST were significantly elevated by DOX and decreased by the combined treatment with GSH (i.g. 5, 50, and $500 \mathrm{mg} / \mathrm{kg}$ per day) (Fig. 2a, b). In the in vitro cell model, DOX $(1,2,5,10$, and $25 \mu \mathrm{M})$ was shown to reduce the survival rate of HL7702 cells in a dose-dependent manner. Exogenous NAC significantly improved the viability of HL7702 cells caused by DOX (Fig. 2c). The concentrations of DOX and GSH in mouse liver were measured to investigate hepatic distribution interactions between DOX and GSH. As shown in Fig. 3, the i.g. administration of GSH had no obvious influence on the exposure levels of DOX in mouse liver. However, the i.p. administration of DOX greatly decreased the GSH concentrations in mouse liver. More importantly, exogenous GSH dosedependently enhanced GSH concentration levels in mouse liver; however, this increased GSH concentration was not directly proportional with dose. These results suggested that exogenous GSH increased intracellular GSH levels and contributed to reduced DOX cardiotoxicity and hepatotoxicity. Furthermore, the enhanced GSH levels did not affect the PK characteristics of DOX.

Although GSH has been shown to reduce the toxicity of DOX, the influence of GSH on the efficacy of DOX is another key factor in determining whether the combined use of DOX and GSH is reasonable. In the current study, the effect of GSH on the antitumor efficacy of DOX was systematically investigated from the PK and PD aspects with in vivo (tumor-bearing nude mice) and in vitro (MCF-7, HepG2, and Caco-2 cells) models. In the PK studies, the i.g. administration of GSH did not significantly influence the target distribution of DOX in mouse tumors (Fig. 4e). Similarly, the combined treatment with NAC, that is, a source of intracellular $\mathrm{GSH}$, had no significant influence on the exposure levels of DOX in MCF-7 cells (Fig. 7b). Thus, GSH did not have a significant impact 
on the PK characteristics of DOX. In the PD studies, treatment of GSH was found to significantly attenuate the antitumor efficacy of DOX in a dose-dependent manner in tumor-bearing nude mice (Fig. 4). Combined treatment with NAC further weakened the cell inhibition of DOX in MCF-7, HepG2, and Caco-2 cells (Fig. 5 and Fig. 6). More importantly, the concentrations of GSH in tumor and cancer cells were measured to elucidate the relationship between GSH and DOX antitumor activity. The results revealed that the GSH levels in the tumors of the DOX-treated group were significantly lower than those in the control group, and the combined use of GSH significantly enhanced the GSH levels in the tumors of DOXtreated mice (Fig. 4c). Exogenous NAC similarly significantly reversed the reduction of GSH levels caused by DOX in MCF-7 cells (Fig. 7a).

In summary, our study provided significant data as follows: (i) treatment with DOX decreased GSH levels in target tissues and cancer cells; (ii) reduced GSH levels could be reversed by exogenous GSH; (iii) exogenous GSH greatly reduced the cardiotoxicity and hepatotoxicity caused by DOX; (iv) combined use of DOX with GSH significantly attenuated the antitumor efficacy of DOX in a dose-dependent manner. The results demonstrated that GSH should be avoided during DOX chemotherapy treatment. When the use of DOX results in obvious hepatotoxicity and cardiotoxicity after chemotherapy, GSH can be used as an antidote to reduce the toxicity caused by DOX. Therefore, the combined use of DOX and GSH contains advantages and disadvantages. GSH should be used to attenuate DOX toxicity, and GSH should not be used to counteract DOX activity in clinical applications.

\section{ACKNOWLEDGEMENTS}

This study was supported by the National Nature Science Foundation of China $(81374054,81573559,81530098)$, the Nature Science Foundation of Jiangsu province (BK20171395), and the outstanding youth fund of State Key Laboratory of Natural Medicines (SKLNMZZJQ201602).

\section{AUTHOR CONTRIBUTIONS}

YL and GJW designed the studies; BYS, CC, YFX, JJS, HMG, HFL, XNL, DK, YHS, $Z P Z$, and $X X Y$ performed the research; BYS and CC analyzed data; and YL wrote the paper.

\section{ADDITIONAL INFORMATION}

Conflict of interest: We declare that we have no financial and personal relationships with other people or organizations that can inappropriately influence our work, there is no professional or other personal interest of any nature or kind in any product, service and/or company that could be construed as influencing the position presented in, or the review of, the manuscript entitled.

\section{REFERENCES}

1. Block KI, Koch AC, Mead MN, Tothy PK, Newman RA, Gyllenhaal C. Impact of antioxidant supplementation on chemotherapeutic toxicity: a systematic review of the evidence from randomized controlled trials. Cancer Treat Rev. 2007;33:407-18

2. Welch JS, Klco JM, Gao F, Procknow E, Uy GL, Stockerl-Goldstein KE, et al. Combination decitabine, arsenic trioxide, and ascorbic acid for the treatment of myelodysplastic syndrome and acute myeloid leukemia: a phase I study. Am J Hematol. 2011;86:796-800.

3. Bachleitnerhofmann T, Gisslinger B, Grumbeck E, Gisslinger H. Arsenic trioxide and ascorbic acid: synergy with potential implications for the treatment of acute myeloid leukaemia? Br J Haematol. 2015;112:783-6.

4. Werneke U. Risk management of nutritional supplements in chronic illness: the implications for the care of cancer and depression. Proc Nutr Soc. 2007; 66:483-92.

5. Reczek CR, Chandel NS. Revisiting vitamin C and cancer: a high dose of vitamin C kills certain colon cancer cells. Science. 2015;350:1317-8.

6. Chandel NS, Ph D, Tuveson DA. Clinical implications of basic research. The promise and perils of antioxidants for cancer patients. N Engl J Med. 2014;371:177-8.
7. Ladas E, Kelly KM. The antioxidant debate. Explor(NY). 2010;6:75-85.

8. D'Andrea GM. Use of antioxidants during chemotherapy and radiotherapy should be avoided. CA Cancer J Clin. 2005;55:319-21.

9. Durken M, Herrnring C, Finckh B, Nagel S, Nielsen P, Fischer R, et al. Impaired plasma antioxidative defense and increased nontransferrin-bound iron during high-dose chemotherapy and radiochemotherapy preceding bone marrow transplantation. Free Radic Biol Med. 2000;28:887-94.

10. Conklin KA. Chemotherapy-associated oxidative stress: impact on chemotherapeutic effectiveness. Integr Cancer Ther. 2004;3:294-300.

11. Kennedy DD, Tucker KL, Ladas ED, Rheingold SR, Blumberg J, Kelly KM. Low antioxidant vitamin intakes are associated with increases in adverse effects of chemotherapy in children with acute lymphoblastic leukemia. Am J Clin Nutr. 2004;79:1029-36.

12. Kennedy DD, Ladas EJ, Rheingold SR, Blumberg J, Kelly KM. Antioxidant status decreases in children with acute lymphoblastic leukemia during the first six months of chemotherapy treatment. Pediatr Blood Cancer. 2005;44:378-85.

13. Cortésfunes $\mathrm{H}$, Coronado $\mathrm{C}$. Role of anthracyclines in the era of targeted therapy. Cardiovasc Toxicol. 2007;7:56-60.

14. Ramos DL, Gaspar JF, Pingarilho M, Gil OM, Fernandes AS, Rueff J, et al. Genotoxic effects of doxorubicin in cultured human lymphocytes with different glutathione $S$-transferase genotypes. Mutat Res. 2011;724:28-34.

15. Zhou F, Hao G, Zhang J, Zheng Y, Wu X, Hao K, et al. Protective effect of 23hydroxybetulinic acid on doxorubicin-induced cardiotoxicity: a correlation with the inhibition of carbonyl reductase-mediated metabolism. $\mathrm{Br} J$ Pharmacol. 2015;172:5690-703.

16. Yeh ET, Tong AT, Lenihan DJ, Yusuf SW, Swafford J, Champion C, et al. Cardiovascular complications of cancer therapy: diagnosis, pathogenesis, and management. Circulation. 2004;109:3122-31.

17. Kalender Y, Yel M, Kalender S. Doxorubicin hepatotoxicity and hepatic free radical metabolism in rats: the effects of vitamin $E$ and catechin. Toxicology. 2005:209:39-45.

18. Zhao $X$, Tong N. Protective effects of berberine on doxorubicin-induced nephrotoxicity in mice. J Transl Med. 2012;10:120-8.

19. Li L, Takemura G, Li Y, Miyata S, Esaki M, Okada H, et al. Preventive effect of erythropoietin on cardiac dysfunction in doxorubicin-induced cardiomyopathy. Circulation. 2006;113:535-43.

20. Yeh YC, Lai HC, Ting CT, Lee WL, Wang LC, Wang KY, et al. Protection by doxycycline against doxorubicin-induced oxidative stress and apoptosis in mouse testes. Biochem Pharmacol. 2007;74:969-80.

21. Wang Y, Mei X, Yuan J, Lu W, Li B, Xu D. Taurine zinc solid dispersions attenuate doxorubicin-induced hepatotoxicity and cardiotoxicity in rats. Toxicol Appl Pharmacol. 2015;289:1-11.

22. Yoda $Y$, Nakazawa M, Abe T, Kawakami Z. Prevention of doxorubicin myocardial toxicity in mice by reduced glutathione. Cancer Res. 1986:46:2551-6.

23. Villani F, Galimberti M, Monti E, Piccinini F, Lanza E, Rozza A, et al. Effect of glutathione and $\mathrm{N}$-acetylcysteine on in vitro and in vivo cardiac toxicity of doxorubicin. Free Radic Res. 1990;11:145-51.

24. Asakura T, Hashizume Y, Tashiro K, Searashi Y, Ohkawa K, Nishihira J, et al. Suppression of GST-P by treatment with glutathione-doxorubicin conjugate induces potent apoptosis in rat hepatoma cells. Int J Cancer. 2001;94:171-7.

25. Ge C, Bei C, Dong F, Fang Z, Zhang J, Na Y, et al. The down-regulation of SLC7A11 enhances ROS induced P-gp over-expression and drug resistance in MCF-7 breast cancer cells. Sci Rep. 2017;7:3791-9.

26. Labriola D, Livingston R. Possible interactions between dietary antioxidants and chemotherapy. Oncology. 1999;13:1011-2.

27. Gouazé V, Mirault ME, Carpentier S, Salvayre R, Levade T, Andrieuabadie N. Glutathione peroxidase-1 overexpression prevents ceramide production and partially inhibits apoptosis in doxorubicin-treated human breast carcinoma cells. Mol Pharmacol. 2001;60:488-96.

28. Yong LC, Brown CC, Schatzkin A, Dresser CM, Slesinski MJ, Cox CS, et al. Intake of vitamins $E, C$, and A and risk of lung cancer The NHANES I Epidemiologic Followup Study. Am J Epidemiol. 1997;146:231-43.

29. Männistö S, Smithwarner SA, Spiegelman D, Albanes D, Anderson K, Brandt PAVD, et al. Dietary carotenoids and risk of lung cancer in a pooled analysis of seven cohort studies. Cancer Epidemiol Biomark Prev. 2004;13:40-8.

30. Jenab M, Riboli E, Ferrari P, Friesen M, Sabate J, Norat T, et al. Plasma and dietary carotenoid, retinol and tocopherol levels and the risk of gastric adenocarcinomas in the European prospective investigation into cancer and nutrition. $\mathrm{Br} J$ Cancer. 2006:95:406-15.

31. Bjelakovic G, Nikolova D, Simonetti RG, Gluud C. Antioxidant supplements for preventing gastrointestinal cancers. Cochrane Database Syst Rev. 2004, 364(4): CD004183.

32. Fisher B, Redmond C, Legault-Poisson S, Dimitrov NV, Brown AM, Wickerham DL, et al. Postoperative chemotherapy and tamoxifen compared with tamoxifen alone in the treatment of positive-node breast cancer patients aged 50 years and 
older with tumors responsive to tamoxifen: results from the National Surgical Adjuvant Breast and Bowel Project B-16. J Clin Oncol. 1990;8:1005-18.

33. Nestal dMG, Vasconcelos FC, Delbue D, Mognol GP, Sternberg C, Viola JP, et al. Doxorubicin induces cell death in breast cancer cells regardless of survivin and XIAP expression levels. Eur J Cell Biol. 2013;92:247-56.

34. Olson RD, Boerth RC, Gerber JG, Nies AS. Mechanism of adriamycin cardiotoxicity: evidence for oxidative stress. Life Sci. 1981;29:1393-401.

35. Davies KJ, Doroshow JH. Redox cycling of anthracyclines by cardiac mitochondria. I. Anthracycline radical formation by $\mathrm{NADH}$ dehydrogenase. J Biol Chem. 1986;261:3060-7.

36. Sazuka $\mathrm{Y}$, Tanizawa $\mathrm{H}$, Takino $\mathrm{Y}$. Effect of adriamycin on the activities of superoxide dismutase, glutathione peroxidase and catalase in tissues of mice. Jpn J Cancer Res. 1989;80:89-94.
37. Doroshow JH, Davies KJ. Redox cycling of anthracyclines by cardiac mitochondria. II. Formation of superoxide anion, hydrogen peroxide, and hydroxyl radical. J Biol Chem. 1986;261:3068-74.

38. Yen HC, Oberley TD, Vichitbandha S, Ho YS, Clair DKS. The protective role of manganese superoxide dismutase against adriamycin-induced acute cardiac toxicity in transgenic mice. J Clin Invest. 1996;98:1253-60.

39. Biesalski HK, Frank J. Antioxidants in cancer therapy: is there a rationale to recommend antioxidants during cancer therapy? Biofactors. 2003;17: 229-40.

40. Conklin KA. Cancer chemotherapy and antioxidants. J Nutr. 2004;134:3201-4.

41. Muralikrishnan G, Amanullah S, Basha MI, Boopalan S, Vijayakumar S, Shakeel F. Effect of vitamin $C$ on lipidperoxidation and antioxidant status in tamoxifentreated breast cancer patients. Chemotherapy. 2010;56:298-302. 